\title{
PENGUKUR TINGGI BADAN MENGGUNAKAN SENSOR ULTRASONIK BERBASIS MIKROKONTROLER ATMEGA328 DENGAN OUTPUT SUARA
}

\author{
Ignatius Agus Supriyono ${ }^{1}$ \\ Ferry Sudarto ${ }^{2}$ \\ Muhammad Khiabani Fakhri ${ }^{3}$ \\ Alumni Universitas Budi Luhur Magister Manajemen ${ }^{1}$, Alumni Universitas Kristen \\ Indonesia $^{2}$, Mahasiswa STMIK Raharja ${ }^{3}$ \\ ignatius@raharja.info'1,ferry.sudarto@raharja.info²,fakhri@raharja.info ${ }^{3}$
}

Diterima : 17 Maret 2015/ Disetujui : 20 April 2015

\begin{abstract}
Measurement is important in the world of science. On these readings on the scale height measuring instrument manual that humans do have a level of accuracy and precision are less so frequent occurrence of human error. Then the required height gauges that can work automatically, perform the measurement process, read the measurement results, as well as notify the measurement results with the ATmega328 microcontroller-based voice output. Digital Height Measuring Circuit uses ultrasonic sensors are used to detect objects around sensor.Jika ultrasonic waves bounce back to the receiver, means there is an object in the vicinity of the sensor. The microcontroller will calculate the time it takes to receive ultrasonic waves and determine the distance between the sensor with the floor. Digital height gauge be important in minimizing human error that often occurs at the time of measurement manually. So as to improve efficiency in measuring height.
\end{abstract}

Keywords : Microcontroller ATMega328, Ultrasonic Sensors , Height

\begin{abstract}
ABSTRAK
Pengukuran merupakan hal yang penting dalam dunia ilmu pengetahuan.Saat ini hasil pembacaan skala pada alat ukur tinggi badan manual yang dilakukan manusia memiliki tingkat ketelitian dan ketepatan yang kurang sehingga sering terjadinya human error. Maka dibutuhkan alat pengukur tinggi badan yang dapat bekerja secara otomatis, melakukan proses pengukuran, membaca hasil pengukuran, sekaligus memberitahukan hasil pengukuran tersebut dengan output suara berbasis Mikrokontroler ATMega328. Rangkaian Pengukur Tinggi Badan Digital ini menggunakan Sensor Ultrasonik yang digunakan untuk mendeteksi benda disekitar sensor.Jika gelombang ultrasonik memantul kembali ke penerima, berarti ada objek di sekitar sensor. Mikrokontroler akan menghitung waktu yang dibutuhkan untuk menerima gelombang ultrasonik dan menentukan jarak antara sensor dengan lantai. Pengukur tinggi badan secara digital menjadi hal penting dalam meminimalisir human error yang sering terjadi pada saat dilakukannya pengukuran secara manual.Sehingga dapat meningkatkan efisiensi dalam mengukur tinggi badan.
\end{abstract}

Kata Kunci: Mikrokontroler ATMega328, Sensor Ultrasonik, Tinggi Badan 


\section{PENDAHULUAN}

Pengukuran merupakan hal yang penting dalam dunia ilmu pengetahuan. Pengukuran-pengukuran tersebut antara lain: pengukuran waktu dari satu kejadian ke kejadian yang lainnya, pengukuran temperatur/suhu suatu daerah, dan pengukuran kecepatan dari suatu benda dan pengukuran tinggi dari satu titik ke titik lain.

Panjang dan tinggi merupakan salah satu besaran fisis yang sering diukur dalam berbagai keperluan yang membutuhkan data tinggi seseorang. Alat ukur tinggi badan yang beredar dipasaran, kurang memungkinkan untuk mendapatkan data yang akurat, karena kebanyakan alat ukur tinggi badan tersebut masih bersifat konvensional atau manual. Artinya untuk mendapatkan data tinggi badan seseorang masih menggunakan pengukuran secara manual.

Hal tersebut berdampak pada pemakaiannya yang kurang efisien. Untuk mengukur tinggi badan seseorang yang dilakukan secara manual yaitu manusia yang bertugas sebagai operator alat untuk mengoperasikannya,kemudian pengukuran tinggi badan dilakukan untuk membaca data yang tampak pada hasil pengukuran tersebut. Hasil pembacaan skala pada alat ukur tinggi badan manual yang dilakukan manusia memiliki tingkat ketelitian dan ketepatan yang kurang.Belum lagi jika sampai terjadi human error.

Dalam penelitian ini, peneliti menggunakan sensor ultrasonik sebagai pengukur tinggi badan berbasis mikrokontroler ATmega328 dengan output suara, alat ini dirancang menyerupai alat ukur tinggi badan pada umumnya yang dilengkapi dengan komponen seperti: Sensor ultrasonik, mikrokontroler, modul suara, dan speaker yang dijadikan sebagai output suara untuk mendukung kinerja alat tersebut.

Alat pengukur tinggi badan ini dapat bekerja secara otomatis, melakukan proses pengukuran, membaca hasil pengukuran, sekaligus memberitahukan hasil pengukuran tersebut dengan output suara berbasis mikrokontroler. Seseorang yang sedang diukur tinggi badannya dapat mengetahui secara langsung hasil pengukurannya.Pembacaan hasil yang didapat lebih akurat dan presisi jika dibanding dengan hasil pembacaan manusia.

\section{PERMASALAHAN}

Pengukuran tinggi badan pada manusia dirasakan cukup penting dalam era globalisasi saat ini.Informasi tentang pengukuran tinggi badan pada umumnya masih dilakukan secara konvensional yaitu menggunakan alat berupa pita meteran dan segitiga siku.Penggunaan alat ukur ini sangat sederhana yaitu dengan memasang pita meteran pada dinding yang tegak lurus dengan lantai kemudian pembacaan pengukuran dilakukan dengan menggunakan segitiga siku dan pembacaan ini dilakukan oleh manusia sebagai operator alat.

Hal ini dapat menyebabkan data dan informasi yang diterima oleh pengguna tidak akurat karena adanya human error saat pembacaan dilakukan.Sebagai salah satu contoh yaitu pada saat seseorang melakukan pengukuran tinggi badan, operator yang membaca hasil pengukuran tersebut salah menyebutkan angka, atau terjadi selisih angka pada saat melakukan pembacaan. Pengukur tinggi badan ini dapat dirancang menjadi otomatis menggunakan sensor ultrasonik berbasis mikrokontroler ATmega328 dengan output suara.

Sensor ultrasonik ini digunakan untuk mendeteksi benda disekitar sensor.Jika gelombang ultrasonik memantul kembali ke penerima, berarti ada objek di sekitar sensor. Mikrokontroler akan menghitung waktu yang dibutuhkan untuk menerima gelombang ultrasonik dan menentukan jarak antara sensor dengan lantai. Dan modul suara yang digunakan sebagai output akan memberikan data sesuai dengan yang diinginkan. 
Bagaimana menggunakan sensor ultrasonik untuk mengukur tinggi badan? Sensor ultrasonik digunakan untuk mendeteksi tinggi badan dengan output suara berbasis mikrokontroler, sehingga ditemukan sebuah solusi yang terbaik bahwa mikrokontroler tersebut memiliki tingkat kehandalan dan kestabilan yang tinggi dan mudah digunakan. Bagaimana memprogram Atmega328 untuk mengukur tinggi badan? Mengkonfigurasi program Atmega328 dengan menggunakan program BASCOM AVR untuk mengetahui tinggi badan yang telah diukur menggunakan sensor ultrasonik dan menghasilkan output suara dari program yang telah terkonfigurasi dengan baik. Bagaimana menghasilkan output suara dari hasil pengukur tinggi badan? Modul suara yang telah dikonfigurasi oleh Atmega328 dihasilkan output suara untuk mengetahui hasil pengukuran secara langsung.

\section{LITERATURE REVIEW}

Banyak penelitian sebelumnya dilakukan mengenai pengukuran berbasis mikrokontroler. Dalam upaya mengembangkan dan menyempurnakan alat ini perlu dilakukan studi pustaka (literature review) sebagai salah satu dari penerapan metode penelitian yang akan dilakukan. Manfaat dari studi pustaka (Literature Review) ini yaitu:

1. Penelitian dalam sebuah jurnal yang telah dilakukan oleh Ferry Sudarto, M.Firman dan Sugeng Adi Atma (2013) berjudul "Tongkat Ultrasonik untuk Tunanetra sebagai Deteksi Jarak Benda dengan Output Suara” ini diusulkan untuk merancang tongkat ultrasonik untuk tunanetra dengan menggunakan teknologi berbasis mikrokontroler yang dapat mendeteksi keberadaan suatu objek. Untuk bisa mendeteksi jarak benda, tongkat ultrasonik dilengkapi oleh berbagai modul diantaranya adalah sensor Ultrasonik D-Sonar untuk mengukur jarak pengguna dengan benda didepannya, mikrokontroler AT89S51 sebagai memori program, dan ISD 2590 sebagai perekam suara untuk output. Gelombang ultrasonik ini akan dipancarkan dan sinyal yang mengenai suatu objek sebagian akan dipantulkan kembali. Sinyal pantul akan diterima oleh suatu penerima untuk kemudian diolah oleh mikrokontroler. Mikrokontroler akan mengontrol dan mengolahnya, sehingga dapat dihasilkan suatu output berupa suara. Dan sebagai pencatu tegangan untuk semua rangkaian digunakan battery.

2. Penelitian dalam sebuah jurnal yang telah dilakukan oleh Yoppy Bagus Budiarto (2012) berjudul "Pengukur Tinggi Badan Digital Dengan Sensor Ultrasonik Berbasis Mikrokontroler AT89S51" ini diusulkan untuk merangkaian Pengukur Tinggi Badan Digital Dengan Sensor Ultrasonik Berbasis Mikrokontroler AT89S51. Adapun rangkaian ini terdiari dari beberapa blok rangkaian. Diantaranya adalah, power supply dengan keluaran sebasar $5 \mathrm{~V}$, blok sensor dengan menggunakan modul sensor Ultrasonik PING, bagian control yang menggunakan mikrokontroler AT89S51, serta output yang berupa Liquid Crystal Display (LCD). Sebuah sensor PING Ultrasonik akan mendeteksi benda di sekitar sensor. Pemancar Sensor akan mengirimkan gelombang ultrasonik. Jika gelombang ultrasonik memantul kembali ke penerima, berarti ada objek di sekitar sensor. Mikrokontroler akan menghitung waktu yang dibutuhkan untuk menerima gelombang ultrasonik dan menentukan jarak antara sensor dengan lantai. Jarak dapat 
dibaca dari Liquid Crystal Display (LCD). Setelah dirakit dan diuji, perangkat ini bekerja dengan baik. Perangkat ini dapat mendeteksi objek sampai dengan jarak $255 \mathrm{Cm}$ dari sensor.

3. Penelitian dalam sebuah jurnal yang telah dilakukan oleh Dita Ditafrihil Fuadah dan Mada Sanjaya WS.Ph.D. (2013) berjudul "Monitoring dan Kontrol Level Ketinggian Air dengan Sensor Ultrasonik Berbasis Arduino" Sensor ultrasonik adalah sensor pengukur jarak dengan menggunakan gelombang ultrasonik. Sensor HY-SRF05 merupakan sensor ultrasonik yang mampu mengukur jarak dari $2 \mathrm{~cm}$ sampai $450 \mathrm{~cm}$. Keluaran sensor ini memungkinkan membaca perubahan jarak pada ketinggian air menggunakan gelombang ultrasonik berbasis Arduino Uno dan dengan interfacing pada Matlab. Pengujian menggunakan bejana bulat denga ketinggian $10 \mathrm{~cm}$.

4. Penelitian dalam sebuah jurnal yang telah dilakukan oleh A. Ejah Umraeni Salam \& Cristophorus Yohannes Jurusan Teknik Elektro Fakultas Teknik Universitas Hasanuddin (2011) berjudul "Pengukur Tinggi Badan Dengan Detektor Ultrasonik”. Penelitian ini membahas tentang pembuatan alat untuk mengukur tinggi badan dengan memanfaatkan sensor ultrasonik. Sensor ultrasonik ini mengirimkan pulsa ultrasonik yang apabila mengenai suatu objek maka pulsa tersebut akan memantul dan diterima kembali oleh receiver sensor tersebut. Output dari sensor ultrasonik ini kemudian akan diolah dengan menggunakan mikrokontroller ATmega8535 kemudian diolah menjadi data dan data tersebut dapat dibaca dengan menggunakan alat display berupa LCD. Pengukur tinggi badan ini menggunakan pemrograman bahasa $C$ yang berfungsi untuk mengolah dan menata sistem kerja rangkaian mikrokontroller ATmega8535 dan rangkaian sensor ultrasonik agar bekerja sesuai dengan yang diharapkan.

5. Penelitian dalam sebuah jurnal yang telah dilakukan oleh Edi Setiawan (2011) berjudul "Alat Ukur Tinggi Badan Digital Menggunakan Ultrasonic Berbasis Mikrokontroleratmega16 Dengan Tampilan LCD”. Penelitian ini membahas tentang pembuatan alat pengukur tinggi badan dengan menggunakan sensor ultrasonic untuk mengitung data dari obyek yang diterima. Sensor ini memiliki ketelitian membaca adanya obyek yaitu 2 - 3 em, sedangkan jarak maksimal yang dapat diterima sensor adalah 300 em, sedangkan pada perancangan ini konstruksi alat yang dibuat yaitu dengan tinggi 200 em tinggi maksimalnya. Sebagai pusat kendali dari alat ukur ini menggunakan Mikrokontroler ATmega16 yang diprogram dengan menggunakan bahasa $\mathrm{C}++$. Sehingga didapat sebuah alat ukur tinggi badan yang mampu mengukur sebuah obyek dengan ketelitian sensor untuk membaca data yaitu $197 \mathrm{~cm}$ tinggi maksimal dan tinggi minimalnya yaitu 110 em. Hanya saja sistem ini masih memiliki tingkat kesalahan total rata-rata sebesar $0.37 \%$ yang dipengaruhi oleh kontruksi alatanya maupun kesalahan dari sensor ultrasonic dalam pengambilan data. Keunggulan dari alat ini yaitu sudah menggunkan teknologi sekarang yaitu mikrokontroler dan sensor, sedangkan untuk tampilan hasil pengukuranya sudah digital yaitu 
dengan menggunakan LCD. Sedangkan kekurangan dari alat ini yaitu dalam kontruksi alatnya dan pembacaan sensornya, sehingga hasil yang diperoleh dari pengukuran masih mengalami kesalahan.

Dari limaLiterature review yang ada, telah banyak penelitian mengenai deteksi jarak benda, alat ukur tinggi badan, mikrokontoler, sensor ultrasonik, dan LCD.Di samping itu juga ada pembahasan mengenai perancangan beberapa alat pengukur tinggi badan yaitu Alat Ukur Tinggi Badan Digital Menggunakan Ultrasonic Berbasis Mikrokontroler Atmega16 Dengan Tampilan LCD, dan Pengukur Tinggi Badan Dengan Detektor Ultrasonik.Namun dapat disimpulkan pula bahwa belum ada peneliti yang secara khusus membahas mengenai perancangan alat pengukur tinggi badan, yang digunakan sebagai alat pendeteksi jarak benda yaitu pengukur tinggi badan secara digital dengan output suara.

\section{PEMBAHASAN}

Untuk bisa membaca tinggi badan, alat ini dilengkapi berbagai modul dan komponen diantaranya adalah power supply, sensor, mikrokontroler, module suara dan speaker. Tanda yang mengarah pada rangkaian power supply sebagai pensuplay tegangan ke seluruh rangkaian alat, sensor yang digunakan adalah sensor ultrasonik SeeedStudio yang akan mendeteksi apabila ada benda atau media lain dibawah sensor tersebut. Ketika sinyal mengenai benda penghalang, maka sinyal akan dipantulkan pemancar (transmitter) dan diterima oleh penerima (receiver) ultrasonik. Sinyal yang diterima oleh receiver di kirimkan ke rangkaian mikrokontroler untuk selanjutnya mengolah dan mengontrol hasil pembacaan yang diterima dari sensor ultrasonik, sehingga dapat dihasilkan suatu informasi tentang keberadaan obyek sekaligus mengukur tinggi antara obyek dengan alat sesuai dengan algoritma program yang dibuat.

Untuk output digunakan module suara sebagai piranti perekam dan pemutar kembali suara yang telah direkam, sebagai perantara antara module suara dengan mikrokontroler maka digunakan speaker yang berfungsi menguatkan keluaran yang dihasilkan. Agar pengukur tinggi badan dapat bekerja sesuai dengan fungsinya tentu saja dibutuhkan pemrograman khusus, oleh karena itu maka perlu dirancang sebuah program yang dibangun menggunakan pemrograman bahasa assembly yang kemudian dikonversikan kedalam bentuk heksa. Program dalam bentuk heksa inilah yang akan dimasukan atau lebih dikenal dengan sebutan injection kedalam mikrokontroler. Data yang diterima oleh mikrokontroler tersebut merupakan data digital hasil konversi dari Analog To Digital Converter (ADC). Untuk memindahkan program dari komputer ke dalam mikrokontroler digunakan downloader yang berfungsi sebagai perantara untuk pengisian program yang disebutkan tadi. Adapun diagram sistem blok secara keseluruhan ditunjukan gambar 2:

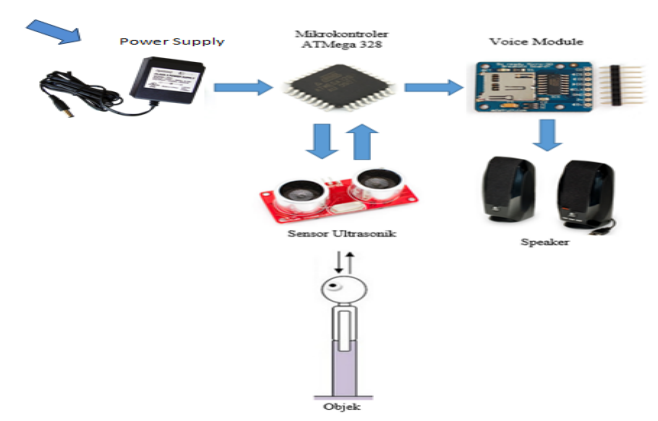

Gambar 1. Diagram Blok Rangkaian 


\section{FLOWCHART SISTEM}

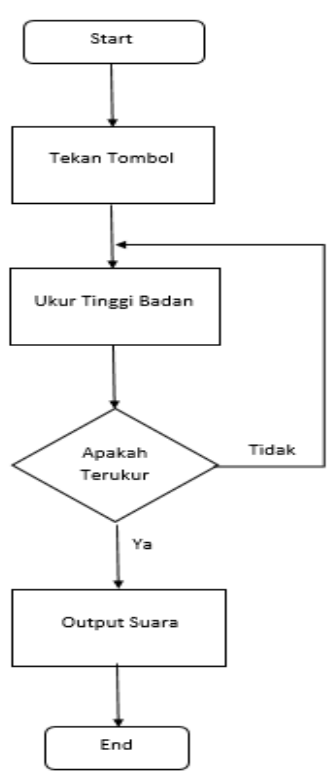

Gambar 2. Flowchart Sistem

Program diawali dengan start yang berarti sistem akan mulai bekerja, kemudian user menekan tombol switch pada alat tersebut untuk mengukur tinggi badan, jika tinggi badan dapat terukur maka output suara akan didapatkan berupa data hasil pembacaan pengukuran. Bila tidak, langkah selanjutnya sistem akan mengulang proses pengukuran dengan menekan ulang tombol pada alat tersebut. Setelah itu tinggi badan telah terukur dan pembacaan oleh sistem berhasil dengan menghasilkan output suara dan akhiri program.

Jika saklar (switch) ditekan, sistem pada alat pengukur sensor ultrasonik akan mulai bekerja dengan mendeteksi adanya benda dan mengukur tinggi badan, yang berarti terjadi proses deteksi pengukuran tinggi badan oleh sensor ultrasonik, pengukuran tinggi badan kemudian akan dikirimkan menuju mikrokontroller yang akan mengolah data lebih lanjut. Mikrokontroler mengolah data yang diterima dari rangkaian sensor ultrasonik untuk dilakukan konversi dari satuan meter yang didapatkan oleh sensor ultrasonik menjadi satuan centimeter. Pada mikrokontroller satuan centimeter yang diperoleh akan dikonversi menjadi data biner yang memiliki address berbeda-beda yang akan menjadi keluaran berupa suara yang mengindikasikan jarak tinggi badan. Bila tidak terdeteksi adanya benda sistem kembali ke kondisi awal.

\section{IMPLEMENTASI}

\section{Pengujian Rangkaian Mikrokontroler} ATmega328

1. Pin 2 (RXD), merupakan jalur untuk melakukan proses penerimaan data pada komunikasi serial.

2. Pin 3 (TXD), merupakan jalur untuk melakukan proses pengiriman data pada komunikasi serial. Pada sistem ini digunakan untuk mengirimkan perintah berupa string ke rangkaian voice module untuk menjalankan voice yang sesuai.

3. Pin 1 (RESET), digunakan untuk proses reset program, yaitu mengembalikan program pada kondisi awal atau baris perintah program seperti pertama kali sistem berjalan.

4. Pin 9 (XTAL1), merupakan pin masukan untuk sumber clock eksternal pada rangkaian mikrokontroler sehingga mikrokontroler akan bekerja dengan kecepatan sesuai dengan nilai dari crystal dan konfigurasi nilai clock pada program.

5. Pin 10 (XTAL2), merupakan keluaran clock yang dapat digunakan untuk sumber clock rangkaian lain yang di rangkai secara serial.

6. Pin 8 dan 22, merupakan ground pada rangkaian mikrokontroler yang terhubung langsung dengan rangkaian ground catu daya.

7. Pin 7 (VCC), 20 (AVCC), 21 (AREF), merupakan pin yang masing-masing pin dihubungkan secara bersamaan pada tegangan 
+5V pada rangkaian catu daya. Ini dilakukan jika pin input analog pada mikrokontroler ATmega8 tidak di fungsikan sebagai Analog to Digital Converter, sedangkan jika pin analog akan digunakan sebagai ADC maka pin 20 dihubungkan pada tegangan $+5 \mathrm{~V}$ melalui lilitan dengan nilai 100uH agar tegangan yang digunakan tidak terpengaruh oleh fluktuatif tegangan kerja pada mikrokontroler. Sedangkan pada pin 21 dihubungkan dengan komponen variabel resistor atau trimpot untuk melakukan pengaturan tegangan referensi yang sesuai dengan kebutuhan dalam aplikasinya.

8. Pin 4 (INT0), merupakan pin yang dihubungkan dengan rangkaian sensor ultrasonik, yang difungsikan sebagai sensor pendeteksi jarak objek yang berada tepat didepan sensor tersebut. pada pin ini merupakan pin yang digunakan sebagai sumber interupsi eksternal pertama pada mikrokontroler Atmega328.

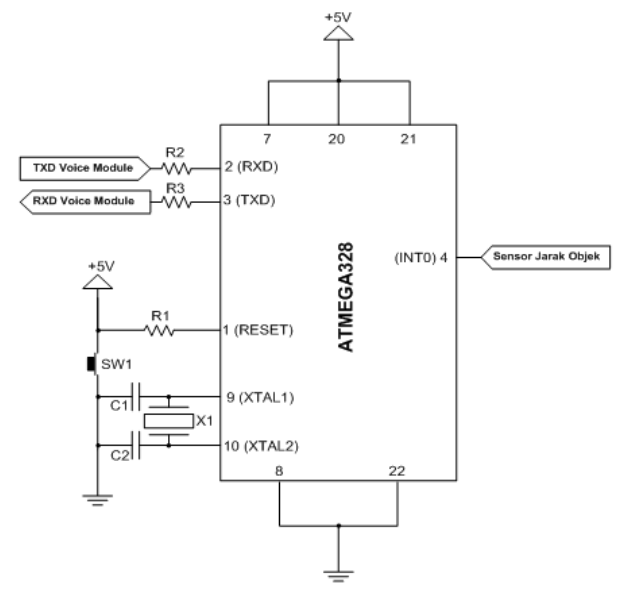

Gambar 3. Rangkaian Mikrokontroller ATMEGA328

Pengujian Rangkaian Sensor Ultrasonik Sensor ultrasonik adalah sebuah piranti yang didesain untuk dapat mentransmisikan gelombang ultrasonik dan menghasilkan pulsa keluaran yang sesuai dengan waktu tempuh untuk pemancaran dan pemantulan gelombang. Dengan menghitung waktu tempuh dari pulsa maka jarak sensor dengan target dapat dengan mudah dihitung, proses pengukuran jarak dilakukan hanya dengan memberikan Trigger dan mendeteksi lebar pulsa Echo seperti pada modul sensor ultrasonik pada umumnya, hasil pengukuran dalam bentuk pulsa dapat ditentukan dengan menghitung lebar pulsa yang keluar pada bagian Echo. Lebar pulsa tersebut mewakili waktu merambatnya sinyal ultrasonik dari sensor ultrasonik ke obyek dan kembali lagi. Sensor ultrasonik bekerja dengan menggunakan tegangan sumber sebesar 5 volt dc, sensor objek ditunjukan pada gambar 5:

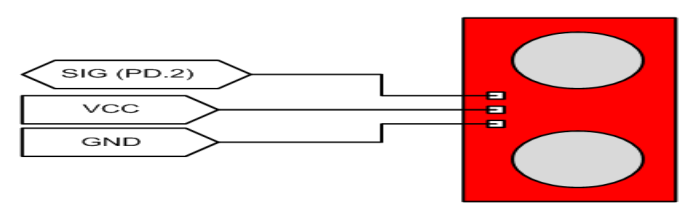

Gambar 4. Rangkaian Sensor Ultrasonik Keterangan:

1. VCC, merupakan masukan untuk tegangan kerja sensor tersebut sebesar $+5 \mathrm{~V}$.

2. GND, dihubungkan dengan kutub negatif atau ground pada rangkaian.

3. OUT, sebagai keluaran yang dihubungkan pada pin PD.2 mikrokontroler ATmega8 yang akan memberikan logika high (1) dan Low (0) pada mikrokontroler untuk mendeteksi adanya objek, sensor ultrasonik bekerja dengan mentransmisikan gelombang ultrasonik dan menghasilkan pulsa keluaran yang sesuai dengan waktu tempuh untuk pemancaran dan pemantulan gelombang. Dengan menghitung waktu tempuh dari pulsa 
makajarak dengan objek dapat dihitung.

\section{Pengujian Rangkaian Voice Module}

Secara keseluruhan pada voice module ini hanya terdapat dua buah komunikasi data secara serial dengan perangkat mikrokontroler.Module ini akan mengeluarkan suara sesuai dengan string yang diterima dari rangkaian mikrokontroler yang terhubung secara serial serta file suara yang tersimpan dalam memori SD card disesuaikan dengan kebutuhan pada aplikasi yang dibuat. Adapun format untuk perangkat $S D$ card yang digunakan adalah menggunakan FAT16 serta format suara yang tersimpan pada memori $S D$ card tersebut dalam bentuk file WAV dan dengan masingmasing pada nama file diinisialisasikan dengan urutan sesuai abjad.

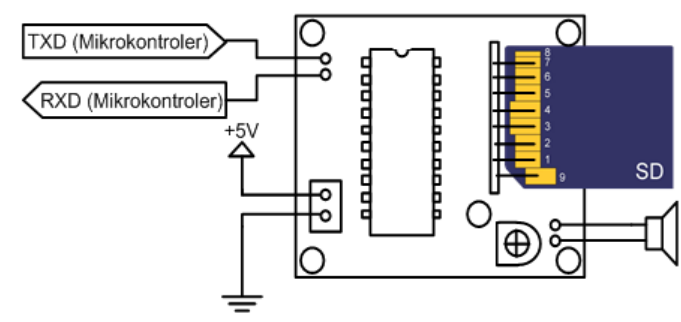

Gambar 5. Rangkaian Voice Module

Keterangan:

1. Pin (RXD), merupakan jalur untuk melakukan proses penerimaan data pada komunikasi serial.

2. Pin (TXD), merupakan jalur untuk melakukan proses pengiriman data pada komunikasi serial. Pada sistem ini digunakan untuk mengirimkan perintah berupa string ke rangkaian voice module untuk menjalankan voice yang sesuai.

\section{PERANCANGAN PROTOTIPE}

Prototipe pengukur tinggi badan menggunakan sensor ultrasonik berbasis mikrokontroler ATmega328 dengan output suara, dalam perancangan disusun menyerupai alat ukur tinggi badan pada umumnya. Alat ini dilengkapi dengan komponen seperti: Sensor ultrasonik, mikrokontroler, modul suara, dan speaker yang dijadikan sebagai output suara untuk mendukung kinerja alat tersebut. Bahan dalam perancangan prototipe terbuat dari besi yang digunakan sebagai tiang.

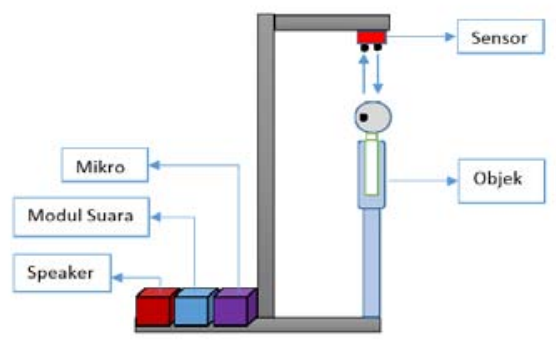

Gambar 6. Perancangan Prototipe

\section{CARA KERJA ALAT}

Cara kerja alat ini cukup sederhana

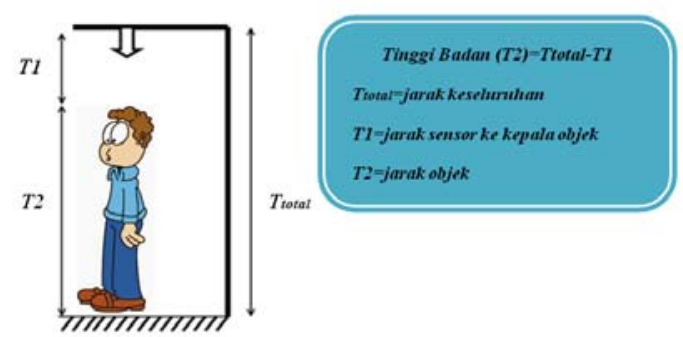

Gambar 7. Cara Kerja Alat

Perhatikan pada gambar diatas. Ttotal adalah tinggi sensor dengan tanah. Pada code nanti, Ttotal akan tertulis 200. Untuk T1 adalah jarak antara sensor dengan kepala atau obyek. Sedangkan T2 adalah hasil dari Ttotal-T2 untuk mengetahui tinggi badan seseorang.

Saat kita berdiri di bawah sensor ultrasonik, maka sensor tersebut akan memantulkan sinyal ultrasonik dari ujung kepala kita (objek yang berdiri di bawahnya) kembali menuju sensor tersebut. Kemudian dapat langsung terbaca melalui Modul Suara dan di keluarkan melalui speaker.

\section{KESIMPULAN}

Dari hasil perancangan alat dan pembahasan pengukur tinggi badan di atas dapat diambil beberapa kesimpulan, di antaranya: 
1. Menciptakan alat pengukur tinggi badan menggunakan sensor ultrasonik berbasis mikrokontroler ATmega328 dengan menghasilkan output suara yang dirancang dan dibuat untuk mendeteksi tinggi badan seseorang sehingga ditemukan solusi terbaik bahwa mikrokontroler memiliki tingkat kehandalan dan kestabilan yang tinggi dan hasil lebih akurat.

2. Proses konfigurasi program ke dalam mikrokontroler ATmega328 mempengaruhi kinerja sistem sensor ultrasonik untuk mendeteksi tinggi badan seseorang dengan menghasilkan output suara.

3. Dari alat pengukur tinggi badan yang telah dirancang dapat mengetahui secara langsung hasil pengukurannya melalui output suara, pembacaan hasil yang didapat lebih akurat dan presisi jika dibanding dengan hasil pembacaan manusia.

\section{DAFTAR PUSTAKA}

[1] A. Ejah Umraeni Salam. Yohannes, Cristophorus. (2011). Pengukur Tinggi Badan Dengan Detektor Ultrasonik. Jurnal. Universitas Hasanuddin. Makassar.

[2] Budiarto. Bagus Yoppy (2012). Pengukur Tinggi Badan Digital Dengan Sensor Ultrasonik Berbasis Mikrokontroler AT89S51. Jurnal. Universitas Gunadarma. Jakarta

[3] Ditafrihil, Fuadah, Dita. Sanjaya, Mada WS.Ph.D. (2013). Monitoring dan Kontrol Level Ketinggian Air dengan Sensor Ultrasonik Berbasis Arduino. Jurnal. UIN Sunan gunung Djati. Bandung.

[4] Sudarto. Ferry, M.Firman dan Adi Atma. Sugeng, (2013). Tongkat Ultrasonik untuk Tunanetra sebagai Deteksi Jarak Benda dengan Output Suara. Skripsi. STMIK Raharja, Tangerang.
[5] Setiawan, Edi. (20011). Alat Ukur Tinggi Badan Digital Menggunakan Ultrasonic Berbasis Mikrokontroleratmega16 Dengan Tampilan LCD. Jurnal. Universitas Gunadarma. Jakarta. 